\title{
Central pain: clinical and physiological characteristics
}

\author{
David Bowsher
}

Pain Research Institute, Walton Hospital, Liverpool, L9 1AE, UK

D Bowsher

Received 4 January 1996 and in final revised form 21 March 1996

Accepted 29 February 1996

\begin{abstract}
Objectives-To study the clinical and pathophysiological features of central pain due to damage to the CNS.

Methods-156 patients (mostly with ischaemic strokes, some with infarct after subarachnoid haemorrhage and other cerebral conditions; one with bulbar and others with spinal pathology) with central pain have been investigated clinically and varying numbers instrumentally with respect to quantitative somatosensory perception thresholds and autonomic function.
\end{abstract}

Results-Pain onset was immediate in a minority; and from a week or two up to six years in $>60 \%$. For those with supraspinal ischaemic lesions, the median age of onset was 59; dominant and nondominant sides were equally affected. Two thirds of the patients had allodynia, including a previously undescribed movement allodynia apparently triggered from group I afferents. Most patients exhibited autonomic instability in that their pain was increased by physical and emotional stress and alleviated by relaxation; cutaneous blood flow and sweating may also be affected. Pain occurred within a larger area of differential sensory deficit. The critical deficit seems to be for thermal and pinprick sensations, which were more pronounced in areas of greatest than in areas of least pain; whereas low threshold mechanoceptive functions, if affected, did not vary between areas of greatest and least pain. Skinfold pinch (tissue damage) pain thresholds were only slightly affected in supraspinal cases, but greatly increased in patients with spinal lesions; thermal (heat) pain did not show this dissociation.

Conclusion-The pathogenetic hypothesis which seems best to fit the findings is that there is up regulation or down regulation of receptors for transmitters, possibly mainly noradrenergic, over time.

$(\mathcal{F}$ Neurol Neurosurg Psychiatry 1996;61:62-69)

spinothalamic pathway, its relays, or projections may cause central pain, ${ }^{8}$ and modern radiological techniques have tended to confirm this. ${ }^{9}{ }^{14}$ Because of this, and of recent considerations on pathophysiology, ${ }^{15-16}$ the condition is now known as "central poststroke pain (CPSP)" ${ }^{17}$ Stroke is not the only condition causing such central pains of cerebral origin. ${ }^{3181923}$ Furthermore, identical pains occur after some spinal lesions. ${ }^{20-22}$

\section{Patients}

Between 1983 and 1993, 156 patients have been referred to me, in whom a diagnosis of central pain due to a cerebral or spinal lesion has been made. Of these, 112 (64 (57)\% male) had a history of a stroke episode (cerebrovascular accident, CVA patients), including four known to have had a cerebral embolus and two known to have had an intracerebral haemorrhage; one had haemorrhage into a tumour (lymphoma). Twelve $(11 \%)$ of these patients were known to have diabetes mellitus, and one had Behçet's syndrome. Nineteen patients (63\% women) had infarcts after subarachnoid haemorrhage (SAH patients); 15 of them had been treated by operation and four conservatively. Four patients (three women) had postoperative infarcts after brain surgery for tumour removal (two vestibular schwannomata, one tentorial meningioma, and one cerebellar haemangioblastoma) and another three men had had brain trauma (one while playing rugby football, one in a street fight, and the other unattributed). One male patient had an enormous arteriovenous malformation involving the thalamus, which had bled on some occasions. Four patients had multiple sclerosis; three had syringo/bulbia/myelia; and three had spinal ischaemic conditions. Seven patients (of whom six are reported elsewhere ${ }^{24}$ ) had postcordotomy dysaesthesia; six had had percutaneous radiofrequency lesions made at $\mathrm{C} 2$ for painful malignant disease, ${ }^{24}$ and the other had had open cordotomy at the thoracic level for sciatica.

Table 1 shows the mean age and the interval between stroke and pain onset and between stroke and presentation at the clinic for the CVA and SAH patients.

Keywords: central pain; sensory thresholds; physiopathological mechanisms

Since the thalamic syndrome was described in $1906,{ }^{1}$ cases with lesions in extrathalamic sites have been described ${ }^{2-7}$; more recently it has been suggested that a lesion anywhere in the

\section{Methods}

Pain quality was assessed by direct interrogation, by the McGill pain questionnaire, ${ }^{25}$ and by free description. Pain intensity was measured by the visual analogue scale. 
Table 1 Demographic characteristics of patients

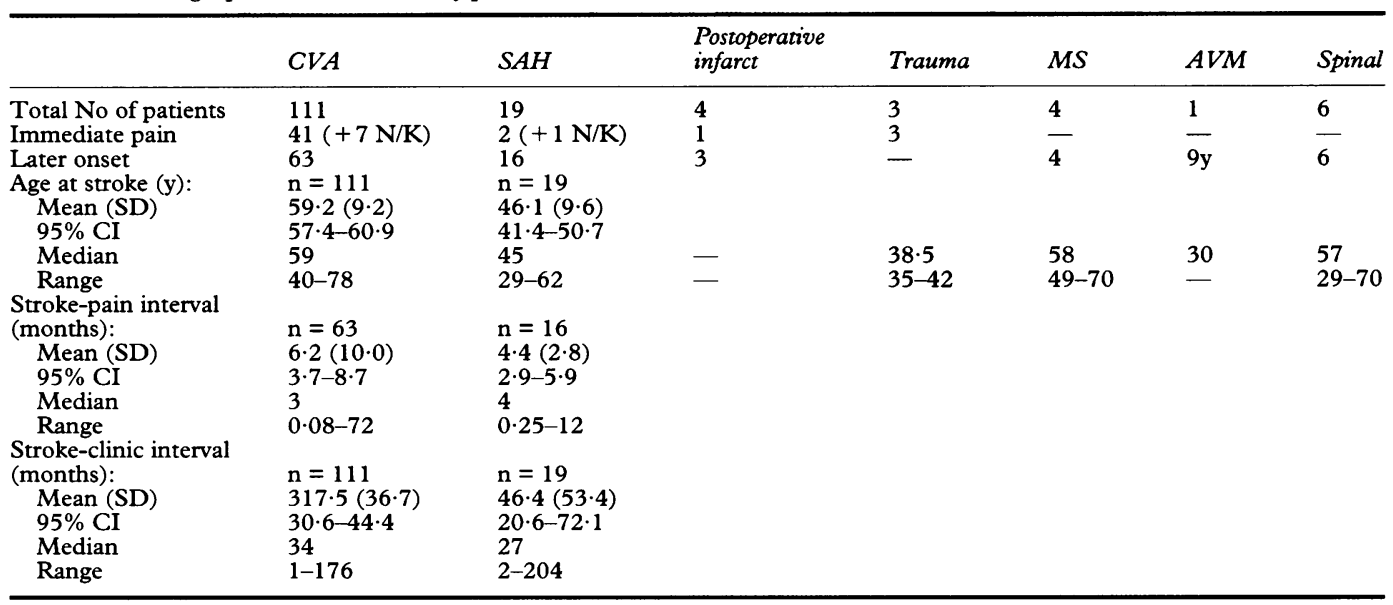

Clinical examination included sensory testing for all somatic modalities and for the presence or absence of allodynia - and its type if present.

In addition, quantitative sensory perception threshold testing was carried out at or soon after first presentation in 61 of the CVA patients, eight of the SAH patients (the findings in seven of whom were reported previously $\left.{ }^{26}\right)$, three postoperative, and two syringomyelic patients. Perception thresholds were established by the method of limits, in all cases using an average of three readings as the value, for the following modalities: touch (von Frey filaments); results were expressed on a logarithmic scale up to $6 \cdot 65$. Patients who could not feel this filament were arbitrarily awarded a score of $7 \cdot 0$; pinprick sensation was assessed with weighted needles, ${ }^{27}$ and results were expressed in g. Patients who could not feel sharpness with the heaviest pin $(5 \cdot 2 \mathrm{~g})$ were arbitrarily awarded a score of 6.0 . Skinfold pinch pain was estimated by the use of forceps coupled to a strain gauge, and the results were expressed in $\mathrm{kg}$. Two point discrimination was measured with Weber's compasses; unobtainable measurements were expressed as $5 \mathrm{~cm}$ on the hand and $10 \mathrm{~cm}$ elsewhere, as actual numbers are required to perform statistical operations. Warmth, coolness, and hot pain were tested with a reversible thermode. ${ }^{28}$ Results were expressed in ${ }^{\circ} \mathrm{C}$ up to $50^{\circ}$ and down to $10^{\circ}$. If patients were unable

Table 2 Distribution of pain

\begin{tabular}{|c|c|c|c|c|}
\hline & $C V A(n=111)$ & $S A H(n=19)$ & $M S$ & Spinal \\
\hline Face + hemibody & $23(21)$ & 4 & 1 & - \\
\hline Hemibody below face & $19(17)$ & 2 & - & - \\
\hline Face only & $8(7)$ & 0 & - & - \\
\hline Face + limbs & $9(8)$ & 0 & - & - \\
\hline Limbs & $25(22 \cdot 5)$ & 5 & - & 3 \\
\hline Face + upper limb & $3(2 \cdot 7)$ & 2 & - & - \\
\hline Trunk + upper limb & 0 & 1 & - & - \\
\hline Upper limb & $10(9)$ & 4 & 1 & 2 \\
\hline Face + lower limb & $1(0 \cdot 9)$ & 1 & - & - \\
\hline Lower limb & $10(9)$ & 0 & 2 & 1 \\
\hline \multicolumn{5}{|l|}{ Other: } \\
\hline Face + both legs & 1 & - & - & - \\
\hline T6 + abdominal viscera & 1 & - & - & - \\
\hline Genitals + both feet & 1 & - & - & - \\
\hline Perineum & 1 & - & - & - \\
\hline
\end{tabular}

Values are numbers of patients (\%). to feel warmth, hot pain, or cold at these temperatures, values of $50^{\circ}$ or $10^{\circ}$ respectively were arbitrarily assigned. All comparisons were made by the the non-parametric MannWhitney method. All measurements were made at four sites: the area of greatest pain $(\max )$ and its contralateral mirror image; and the area of least pain (min) and its contralateral mirror image.

Skin temperature was measured with an electronic skin thermometer in 42 cases; absolute values were obtained and so comparisons were made with paired or unpaired $t$ tests. In 48 other cases, skin blood flow was assessed by means of liquid crystal contact thermography.

\section{Results}

\section{CLINICAL FINDINGS}

Table 2 shows the extent of the painful area. In almost all cases, there were regions where the pain was felt to be "worse" or more intense than in other areas. These are referred to as areas of maximum pain $(\max )$ and areas of minimum pain (min). These differences persisted despite overall fluctuations in intensity (see below), but sometimes varied over time, often apparently as a result of treatment.

Such broad categories, although necessary, fail to take account of regions within regions. Thus two patients with facial pain had only one trigeminal area affected; whereas many with pain in the limbs had either the proximal limb areas or the extremities maximally affected. One man had abdominal pain together with girdle pain in the T8 dermatome; one woman had only the left side of her vulva and vagina involved. It was not uncommon, particularly in patients with the cheiro-oral syndrome or crossed (brainstem) stroke, to find pain in one site and painless sensory change in the other.

None of the patients with postoperative infarcts or head injury showed any striking differences on clinical or laboratory testing from patients who had had spontaneous infarcts.

Table 3 shows the non-sensory clinical features of the patients. In the great majority the motor deficit was relatively mild and the 
Table 3 Non-sensory features of patients

\begin{tabular}{|c|c|c|c|c|c|c|}
\hline & $C V A$ & $S A H$ & $\begin{array}{l}\text { Postoperative } \\
\text { infarct }\end{array}$ & Trauma & $M S$ & Spinal \\
\hline $\begin{array}{l}\text { Total No of patients } \\
\text { Male } \\
\text { Dominant side affected } \\
\text { Crossed stroke } \\
\text { Aphasia } \\
\text { Dysphasia } \\
\text { Hemimonoplegia } \\
\text { Hemimonoparesis } \\
\text { Extrapyramidal signs } \\
\text { Hyperhidrosis } \\
\text { Jacksonian fits }\end{array}$ & $\begin{array}{l}111 \\
63(57) \\
57(54) \\
11(10) \\
6(5) \\
8(7) \\
9(8) \\
32(29) \\
8(7) \\
7(6) \\
6(5) \\
\text { three painful }\end{array}$ & $\begin{array}{l}19 \\
11(58) \\
9(47) \\
1 \\
-3(16) \\
14(74) \\
3(16) \\
2 \\
4 \\
4(21) \\
\text { all postoperative; } \\
\text { one with painful area }\end{array}$ & $\begin{array}{l}4 \\
1\end{array}$ & $\begin{array}{l}3 \\
3\end{array}$ & $\begin{array}{l}4 \\
0\end{array}$ & 6 \\
\hline
\end{tabular}

Values are numbers of patients (\%).

Table 4 Spontaneous pain description

\begin{tabular}{lllllll}
\hline & $C V A$ & $S A H$ & $\begin{array}{l}\text { Postoperative } \\
\text { infarct }\end{array}$ & Trauma & MS & Spinal \\
\hline Total No of patients & 108 & 19 & 4 & 3 & 4 & 6 \\
Burning or scalding & $51(47 \%)$ & $8(42 \%)$ & $3(75 \%)$ & $3(100 \%)$ & $4(100 \%)$ & $5(83 \%)$ \\
Aching or throbbing & $37(34 \cdot 5 \%)$ & $7(39 \%)$ & $1(25 \%)$ & - & - & $1(17 \%)$ \\
Shooting or stabbing & $8(7 \cdot 4 \%)$ & $2(11 \%)$ & - & - & - & - \\
Painful pins and needles & $6(5 \cdot 6 \%)$ & $2(11 \%)$ & - & - & - \\
\hline
\end{tabular}

Values are numbers of patients (\%).

patients were ambulant; the six aphasic patients were among the eight who had profound monoplegia or hemiplegia. At presentation in the clinic, 11 of 111 CVA patients $(10 \%)$ had had what seemed to be pure sensory strokes.

Table 4 shows the subjective quality of the pain as described at interview. McGill questionnaires yielded broadly similar results.

Table 5 shows exacerbating factors for CVA and SAH patients. They were volunteered by some patients, and from others they were elicited by means of a checklist. Two or more of these factors were mentioned by some patients. Other exacerbating factors mentioned, alone or in combination, included

Table 5 Exacerbating factors in CPSP after CVA and $S A H$

\begin{tabular}{lcc}
\hline & $C V A(n=100)$ & $S A H(n=15)$ \\
\hline None & 9 & 0 \\
All stress & $46(46)$ & $8(53)$ \\
All cold & $48(48)$ & $10(67)$ \\
All warm & $8(9)$ & 0 \\
All orgasm & $9(10)$ & 1 \\
Exercise/fatigue & 1 & 1 \\
Stress + cold & $28(28)$ & $4(17)$ \\
Stress + cold + warm & $2(3)$ & 0 \\
Stress + orgasm & $2(3)$ & 0 \\
Cold + orgasm & $2(3)$ & 0 \\
Stress + cold + orgasm & $2(3)$ & 0 \\
\hline
\end{tabular}

Values are number of patients (\%); "All” refers to all patients with this feature, with or without others.

Table 6 Types of allodynia in central pain due to various supraspinal causes

\begin{tabular}{llllll}
\hline & $\begin{array}{l}\text { CVAn } \\
(n=92)\end{array}$ & $\begin{array}{l}\text { SAHn(\%) } \\
(n=14)\end{array}$ & $\begin{array}{l}\text { Trauma } \\
(n=1)\end{array}$ & $\begin{array}{l}\text { Postoperative } \\
\text { infarct } \\
(n=3)\end{array}$ & $\begin{array}{l}\text { AVM } \\
(n=1)\end{array}$ \\
\hline No allodynia & $26(28)$ & $3(21)$ & - & - & - \\
All tactile & $48(52)$ & $9(64)$ & - & 1 & - \\
All movement & $20(22)$ & $2(14)$ & - & - & - \\
All thermal & $18(19 \cdot 5)$ & $2(14)$ & 1 & 1 & - \\
Tactile + thermal & $8(9)$ & $1(7)$ & - & - & - \\
Tactile + movement & $11(12)$ & $1(7)$ & - & - & - \\
Thermal + movement & $1(1)$ & - & - & & - \\
\hline
\end{tabular}

"All" refers to all patients with this feature, with or without others

^In two patients with CVA, warmth and cold; in two others, warmth only; but in all patients with SAH, traumatic and postoperative cases, and 14 other patients with CVA, cold.

In 10 patients with CVA and four with SAH, the presence or absence of allodynia was not known due to a/dysphasia or inability of patient to respond reliably. bright lights (thrice), loud noises (twice), physical pressure (twice), and micturition once (by the patient with perineal pain).

Identifiable exacerbating and alleviating factors were independent of the apparently spontaneous fluctuations in pain severity reported by most (but not all) patients.

Jacksonian fits were experienced by six CVA patients and one postoperative patient at the time they were being treated for CPSP. In five of these patients, the fits began in the area of maximum pain and were preceded by a painful aura in that region in four patients. Fits had been prevented or were controlled in all patients with $\mathrm{SAH}$, and other postoperative and post-traumatic patients by the time they came under my care.

Table 6 illustrates allodynia, defined as the provocation of pain by a brief and normally innocuous stimulus. Allodynia was recorded in 66 out of $92(72 \%)$ patients with CPSP after CVA, and in 11 out of $14(79 \%)$ patients with CPSP after SAH (table 6); and in both patients with syringomyelia and three of the four patients with spinal ischaemic lesions. Three types of allodynia were found: cutaneous, caused by a low intensity stimulus moving across the skin; although in eight CVA patients the required provoking stimulus was slightly more intense and prolonged, and could best be described as rubbing. In no case was pain provoked by maintained pressure; indeed this was often thought to have an alleviating effect. Thermal allodynia was caused by contact of a cold object (in two cases only, a warm stimulus) with the skin. The third type, movement allodynia, does not seem to have been described previously; it was seen in $22 \%$ of CVA and $14 \%$ of SAH patients, and was brought about by isotonic or isometric muscle contraction; some patients felt virtually no pain if they kept quite still. About a quarter of the patients with allodynia had more than one type. One CVA patient judged to have no true allodynia was startled by all stimuli. 
Table 7 Sensory deficit on clinical examination in patients with infarcts after stroke or $S A H$

\begin{tabular}{|c|c|c|c|c|c|}
\hline & $C V A$ & $S A H$ & Trauma & $\begin{array}{l}\text { Postoperative } \\
\text { infarct }\end{array}$ & Spinal \\
\hline Total no of patients & 92 & 13 & 3 & 4 & 6 \\
\hline None $^{\star}$ & 1 & 0 & 1 & - & - \\
\hline Tactile only & 0 & 2 & - & - & - \\
\hline Pinprick only & 6 & 1 & 1 & - & - \\
\hline Thermal only & 9 & 0 & - & - & - \\
\hline All three & 36 & 1 & - & 1 & 6 \\
\hline Tactile + pinprick & 8 & 1 & - & - & - \\
\hline Thermal + pinprick & 28 & 4 & - & 3 & - \\
\hline Tactile + thermal & 4 & 4 & 1 & - & - \\
\hline All with tactile deficit & 48 & 8 & 1 & 1 & 6 \\
\hline All with thermal deficit & 74 & 9 & 2 & 4 & 6 \\
\hline All with pinprick deficit & 78 & 7 & - & 4 & 6 \\
\hline Skinfold pinch deficit & - & - & - & - & 6 \\
\hline $\begin{array}{l}\text { All with thermal and } \\
\text { pinprick deficit }\end{array}$ & 68 & 5 & 0 & 4 & 6 \\
\hline $\begin{array}{l}\text { All with thermal and/or } \\
\text { pinprick deficit }\end{array}$ & 91 & 11 & 3 & 0 & 0 \\
\hline
\end{tabular}

Instrumental examination never failed to disclose a sensory deficit (table 8 ).

Sensory impairment was clinically determined in most patients; in a few, instrumental measurement alone was used. Table 7 shows the results.

Only one CVA patient and none of the SAH patients failed to exhibit a clinically evident impairment of one or both small fibre modalities.

There were four noteworthy features about these somatosensory impairments:

(1) The area of sensory impairment was always more extensive than the painful areafor example, a patient with a right hemibody sensory deficit complained of pain only in the cheek. However, the discordance was usually less dramatic than this.

(2) The degree of impairment was greatest in the region of greatest pain.

(3) There were evident quantitative differences between modalities: tactile impairment was almost always slight, whereas thermal and pinprick deficits were much more severe. Many patients showed only a small area of tactile deficit, whereas the areas of pinprick and thermal impairment were much bigger; and the latter were often, though not always, coextensive.

(4) Whereas change (if any) in large fibre sensations was the same in areas of maximal and minimal pain, changes in sharpness (pinprick) and thermal sensations were less in areas of minimal than of maximal pain.

One patient, with pain in the cheek and side of the nose (but with sensory change over a much larger area), had digitally removed the ala nasae on the affected side, such that there was a gap about the shape and size of a little fingernail in the side of his nose. This was the only instance of self mutilation ("autotomy") found.

The results of quantitative sensory threshold perception tests in all patients with supraspinal lesions turned out to be remarkably similar, so the results have been pooled in table 8 , which shows the differences between median values for area of maximum and minimum pain in comparison with their contralateral mirror image areas; and also a direct comparison between values in areas of maximum and minimum pain. The significance of differences has been calculated by the MannWhitney test.

In fact, tactile perception threshold was equal on the two sides in $10 \mathrm{CVA}$ and two SAH patients and one postoperative patient, and was unaffected in all patients with spinal lesions; values on the unaffected side were higher than on the affected side in four CVA patients; two point discrimination was equal on the two sides in four CVA patients and one postoperative patient; pinprick threshold was the same on both sides in two CVA patients, and higher on the unaffected side in four CVA patients and one SAH patient; pinch threshold was also equal in three CVA patients, one patient with SAH, and one postoperative patient, but apparently higher on the unaffected side in eight CVA patients; warm threshold was the same on both sides in two CVA patients and higher on the unaffected side in another six; cold threshold was the same on both sides in two CVA patients and lower on the unaffected side in another four; hot pain threshold was equal on both sides in two CVA patients and higher on the unaffected side in five CVA patients and one SAH patient; whereas skin temperature was the same on both sides in four CVA patients and lower on the unaffected side in another eight CVA patients, one SAH patient, and two postoperative patients.

Instrumentally measured thresholds for tactile and temperature perceptions were compared in five patients with crossed sensory change (assumed to have lower brainstem lesions) and the other CVA and SAH patients (assumed to have supratentorial lesions). There were no discernible differences between

Table 8 Supraspinal central pain: Differences between medians of max and mirror max, min and mirror min, and between max and min

\begin{tabular}{|c|c|c|c|c|}
\hline & Max-mirror $\max (n)$ & Min-mirror $\min (n)$ & Max-min & Pvalue \\
\hline Touch (von Frey) & $1.13 \log$ units $^{\star \star \star}[40 \%](75)$ & $0.71 \mathrm{log}$ units $^{\star \star \star}[25 \%](69)$ & $0.32 \log$ units & $0.09 \mathrm{NS}$ \\
\hline Vibration & $1.0 \mu \mathrm{m}$ NS $[133 \%](26)$ & $0.69 \mu \mathrm{m}$ NS $[56 \%](22)$ & $0.31 \mu \mathrm{m}$ & $0.4 \mathrm{NS}$ \\
\hline Two point discrimination & $3.8 \mathrm{~cm}^{\star \star \star}[190 \%](26)$ & $2.75 \mathrm{~cm}^{\star \star}[55 \%](24)$ & 0 & $0.36 \mathrm{NS}$ \\
\hline Skinfold pinch & $2 \cdot 1 \mathrm{~kg}^{\star \star}[26 \%](46)$ & $2 \cdot 5 \mathrm{~kg}^{\star \star}[37 \%](41)$ & $-0.4 \mathrm{~kg}$ & $0.2 \mathrm{NS}$ \\
\hline Pinprick & $2 \cdot 0 g^{\star \star \star}[125 \%](50)$ & $0.95 \mathrm{~g}^{\star \star \star}[59 \%](48)$ & $1.05 \mathrm{~g}$ & $0.02^{\star}$ \\
\hline Warm & $6 \cdot 2^{\circ} \mathrm{C}^{\star \star \star}[17 \%](75)$ & $4 \cdot 1^{\circ} \mathrm{C}^{\star \star \star}[11 \%](69)$ & $2 \cdot 1^{\circ} \mathrm{C}$ & $0 \cdot 02^{\star}$ \\
\hline Cold & $-6 \cdot 0^{\circ} \mathrm{C}^{\star \star \star \star}[-21 \%](73)$ & $-3.4^{\circ} \mathrm{C} \star \star[-12 \%](68)$ & $-2 \cdot 6^{\circ} \mathrm{C}$ & $0.03^{\star}$ \\
\hline Hot pain & $3 \cdot 1^{\circ} \mathrm{C}^{\star \star \star}[7 \%](75)$ & $1.8^{\circ} \mathrm{C}^{\star \star}[2 \%](69)$ & $1 \cdot 3^{\circ} \mathrm{C}$ & $0.06 \mathrm{NS}$ \\
\hline Skin temperature & $-0 \cdot 2^{\circ} \mathrm{C}^{\star}[0 \cdot 6 \%](42)$ & $0^{\circ} \mathrm{C}^{\star}[0 \%](37)$ & $-0.7^{\circ} \mathrm{C}$ & $0.4 \mathrm{NS}$ \\
\hline
\end{tabular}

Figures in square brackets are $\%$ changes with respect to mirror (= control) values. $\star \mathrm{P}<0.05 ; \star \star \mathrm{P}<0.009 ; \star \star \star \mathrm{P}<0.0009$

In no case was there a significant difference between mirror max and mirror min.

Set out in this way, it is easier to see that although all modalities are affected, only pinprick, warm, and cold deficits are quantitatively related to pain intensity; hot pain just fails to reach significance. 
the two groups to tactile or cold stimulation, but there were significant differences for warm and hot pain thresholds.

Thresholds were measured in two patients with syringomyelia. Both had raised thresholds for touch and two point discrimination; skinfold pinch thresholds were unobtainable in both patients in the most painful hand; thermal thresholds were unobtainable in one patient and significantly raised in the other.

Autonomic function was assessed in 42 instances by measurement of skin temperature, and in 48 others the relative temperature of the skin on the two sides was measured by liquid crystal contact thermography. Skin temperature measurement in areas of maximal but not of minimal pain, compared with their mirror image areas on the unaffected side, showed the affected area to be significantly cooler $(\mathbf{P}=0.05$; table 8$)$. Thermographic assessment of skin temperature, carried out in the clinic, showed cutaneous vasoconstriction in the affected area in more than two thirds of the patients in whom it was performed.

Sweat production at rest was measured by evaporimetry in the maximally affected area and its mirror image in 13 CVA patients and in the minimally affected area and its mirror image in 10 . In the maximally affected area, sweat production was higher than in the mirror image area in eight out of 13 patients, and lower in five, whereas in the minimally affected area, it was higher in eight out of 10 instances and lower in only two.

\section{Discussion}

It is not known exactly how many stroke patients have central pain, but the figure has been put at $1 \cdot 5-2 \cdot 0 \%$ of all strokes, ${ }^{29}$ although Andersen $e$ al $^{30}$ estimate it as being as high as $8 \%$.

What is immediately striking about the group of stroke patients reported here is the relatively young median age (57) at which they had their strokes (table 1), in comparison with the whole stroke population, whose median age is $75 ; 69 \%$ of our patients, but only $25 \%$ of all stroke patients, are under 65. Leijon et $a l^{31}$ reported 27 CVA patients with a mean age of 62 , whereas the median age of the 11 prospectively identified CVA patients of Vestergaard et al ${ }^{32}$ was 74 . Although it is just possible that older stroke patients who develop CPSP are not referred, it seems unlikely; in which case there is a genuine and significant age difference from the general stroke population.

It is of interest that the ischaemic lesion in some $15 \%$ of patients with CPSP followed SAH. This was not just due to postoperative infarction, such as occurred in four other neurosurgical patients reported here, because in four out of 19 SAH patients $(21 \%)$ ischaemia was consequent on non-surgical treatment; and a case has recently been reported in a patient with an unruptured aneurysm. ${ }^{33}$ If the four cases of postoperative infarct in the present report are added, the proportion of patients with CPSP with non-stroke cerebral pathology in the present series rises to $17 \%$, and further addition of the three posttraumatic cases takes the figure to $19 \%$.

Pain onset is only immediate in a minority of patients-37\% in the present series for CVA patients, only two out of $18 \mathrm{SAH}$ patients, but immediate in the three posttraumatic patients (table 1); it was late in at least three of the four cases of spinal infarct, and postdated the onset of other symptoms in syringomyelia/bulbia and multiple sclerosis. Garcin ${ }^{6}$ comments on the late onset in CVA, which Leijon et $a^{31}$ and Boivie and Leijon ${ }^{34} 35$ found to occur within the first month in more than half of their 27 cases; three out of 11 patients in the Danish series ${ }^{32}$ developed pain within a month. It is interesting to note that the median interval is very similar to that preceding the onset of postcordotomy dysaesthesia. A possible explanation for late pain onset is discussed below. With a median onset time in well over half of all the present CVA patients of three or four months, it means that most patients will have returned to the community, often under the supervision of a primary care physician, before the pain declares itself. It is of very great interest that a substantial number of patients reported that their pain began as motor recovery took place.

The commonest description of the pain is as paradoxical burning - that is, like the burning sensation induced by immersion of the hand in iced water ( $47 \%$ spontaneously, $73 \%$ using the McGill questionnaire; $59 \%$ in the series of Leijon et $a l^{31}$ ). Such a description is indistinguishable from that given by patients with other types of neurogenic pain of central (syringomyelia, some cases of multiple sclerosis, postcordotomy dysaesthesia) or supposedly peripheral (reflex sympathetic dystrophy, postherpetic neuralgia, painful diabetic neuropathy) origin. However, the words "cold" or "freezing" are not often marked in the McGill pain questionnaire by patients with types of pain other than CPSP, perhaps because larger areas of the body are usually involved in CPSP. Paradoxical burning has been reported $^{36}$ after blockade of cold specific myelinated fibres in the periphery, and may further be explained by the recently described central disinhibition caused by Thunberg's grill of interlaced warm and cold bars. ${ }^{37}$ The principally aching type of pain is also occasionally seen in postherpetic neuralgia (especially when the original shingles has been treated with acyclovir ${ }^{38}$ ), but is more frequent in CPSP. Unlike urent pain, it does not distinguish neurogenic from nociceptive pain.

The distribution of pain is somewhat haphazard (table 2), particularly when the area of greatest pain is considered, and no clear pattern emerges. Maximal (or even only) pain is as likely to occur in the proximal parts of limbs or on the trunk as in the extremities. In some cases the area of pain is so small that when it is on the face, a differential diagnosis from trigeminal neuralgia has to be consideredthis happened in two cases in the present series, and has been reported previously. ${ }^{39}$ It is an astonishing coincidence that all 11 cases 
recently reported by Vestergaard et $a l^{32}$ had pain in the thenar eminence. Leijon et al ${ }^{31}$ found hemibody pain, with or without facial involvement, in $74 \%$ of their 27 patients, whereas only $38 \%$ of the present CVA series have such widespread distribution. Cheirooral distribution is emphasised by $\mathrm{Garcin}^{20}$ and might be expected in true "thalamic syndrome" as so many neurons in the human ventroposterior thalamic nucleus have receptive fields in the hand and mouth regions. ${ }^{40}$ What should be stressed, as has recently been mentioned by Vestergaard $e t a l,,^{32}$ is that the pain, whatever its location, always occurs within a larger area of sensory change.

The right-left distribution was virtually equal in our CVA patients (table 3) $(54 \%$ affected on the dominant side), and in the 11 Danish cases, ${ }^{32}$ whereas it was $33 \%-67 \%$ in the 27 patients of Leijon et al $^{31}$ and there was a much higher non-dominant side in the 87 patients of Kameyama. ${ }^{41}$

Ten per cent of the present CVA patients presented crossed sensory symptoms (table 3), without necessarily having pain in the face; their symptoms were therefore attributed to lower brainstem infarct (Wallenberg's syndrome). Garcin ${ }^{620}$ and Riddoch ${ }^{42}$ point out that upper brainstem strokes do not necessarily give rise to crossed symptoms, as reported earlier ${ }^{6434}$; a painless case with MRI confirmation has recently been noted. ${ }^{45}$

The relative mildness of the motor deficit in most cases (table 3) is also noteworthy, and has been commented on by previous authors, beginning with Dejerine and Roussy ${ }^{1}$ themselves. Ten per cent of the CVA patients in the present series could be classified as pure sensory stroke, and only $8 \%$ of CVA patients with and $17 \%$ of patients after SAH were hemiplegic or monoplegic, and $13 \%$ aphasic or dysphasic ( $7 \%$ for the patients reported by Leijon et $a l^{31}$ ). Apart from main thalamique (said to be present in $25 \%$ of thalamic cases $^{46}$ ), extrapyramidal signs were seen in only $6.5 \%$ of our patients, and $4 \%$ of the 27 reported by Leijon $e t$ al, ${ }^{31}$ despite the fact that extrapyramidal signs were signalled as a criterion in the original publication of Dejerine and Roussy. ${ }^{1}$ However, Davison and Schick ${ }^{3}$ could find only five cases with extrapyramidal signs in the by then extensive medical literature.

Seven patients (including one with a postoperative infarct) in the present series had Jacksonian fits, five with a painful aura. This has been commented on by Head and Holmes $^{2}$ and Riddoch, ${ }^{42}$ and was reported in three of the 12 patients with pain after a cortical infarct described by Michel et al. ${ }^{5}$

Allodynia was experienced by two thirds of the patients with CPSP (table 6). This is to be compared with $>90 \%$ of patients with postherpetic neuralgia (see below). Except for the case of a woman with CPSP who experienced extreme agony when any part of the affected hemibody was touched howbeitsoever lightly (as in the patient in whom it was provoked by a fly walking on the face ${ }^{47}$ ), allodynia tended to trouble patients with central pain somewhat less than it did patients with postherpetic neu- ralgia, in whom it was often the cardinal symptom. ${ }^{48}$ However, some of the present patients with allodynia in the hand always wore a glove, and several of our patients reported allodynia caused by taking a shower or being rained on. In CPSP, allodynia was often obtained from only a small area within the whole painful area (which itself was smaller than the whole area of sensory change). Tactile allodynia was the commonest form, occurring in half the allodynic cases, and could sometimes be obtained from outside the painful area. As in postherpetic neuralgia, ${ }^{49}$ it was triggered only by moving stimuli-that is, from rapidly adapting low threshold mechanoreceptors. Also as in postherpetic neuralgia, firm contact (pressure)that is, stimulation of slowly adapting low threshold mechanoreceptors - often relieved pain, and even when it did not, never caused allodynia. Head and Holmes ${ }^{2}$ make the point that the degree of allodynia is unrelated to the degree of sensory deficit; their statement is borne out by the present findings.

An exception must also be made for some cases of movement allodynia (experienced by one third of patients with CPSP and allodynia): several patients felt no pain at all if they kept still, but the slightest movement induced great pain. Other patients with movement allodynia experienced background pain which was exacerbated by movement. Movement allodynia has not been previously described, although Garcin ${ }^{6}$ mentions exacerbation of pain by movement. In my experience it is extremely rare except in CPSP. As it occurs on isometric as well as isotonic muscle contraction, it may be assumed to be triggered from primary afferents arising in muscle spindles or tendons.

Exacerbation of pain by factors including stress and environmental cold (table 3 ), as well as by noise ("music" 42 ), was reported by early authors, most of whom emphasise the primacy of "emotion" or "anxiety" (called "stress" in table 5). This affected nearly half of the patients reported here, but only one fifth of the Swedish patients, ${ }^{31}$ although, like the present series, about half of them were affected by environmental cold.

Autonomic disturbance in central pain syndromes was remarked on by Garcin, ${ }^{20}$ who specifically noted "modifications of temperature" such as reported here with respect to skin temperature. Autonomic instability is evidenced by the ability to fall asleep easily, meaning that the pain is less when the subject is relaxed, and exacerbation by some of the factors mentioned above, particularly environmental (cold) and emotional stress. However, 11 of our patients volunteered the fact that orgasm, representing an enormous autonomic discharge, greatly increased their pain; this has not been previously reported. It is true, of course, as mentioned by Boivie and Leijon, ${ }^{35}$ that many autonomic changes, particularly cutaneous vasoconstriction, occur in painfree stroke patients; taking our patients as a whole, the area of greatest pain showed a just significant lowering of resting skin temperature. Contact thermography, when performed, usu- 
ally showed areas of greatest pain to be colder than areas of least pain; many of the patients spontaneously mentioned that they felt particularly cold in the area of greatest pain when the pain was bad; unfortunately it never proved possible to measure skin temperature in periods of mild and severe pain in the same patient. It has been noted ${ }^{50}$ that the cutaneous vasoconstriction can be reversed by low dose calcium channel blockers, without affecting the pain.

Hyperhidrosis has also been reported in $85 \%$ of painfree stroke patients ${ }^{51}$ although these authors correlate it with upper motor neuron deficit, which was not necessarily the case in our patients.

From a pathophysiological point of view, the most interesting feature concerns the nature of the sensory deficit (table 6). One half of the patients have a tactile deficit in addition to other forms of sensory loss, but only a minute proportion (on clinical testing only) have an isolated tactile deficit, although this is common in stroke patients without pain. ${ }^{29}$ Almost all (97\%) patients with central pain have a deficit of pinprick and/ or thermal sensations, as noted by Schmahmann and Leifer ${ }^{52}$; and the latter seems to affect warm and cold sensations to a far greater extent than hot pain, as also found by Vestergaard et al. ${ }^{32}$ Because there is no peripheral involvement in stroke, the sensory deficit must be ascribed to a disturbance of central processing of information arriving from $\mathrm{A} \delta$ and $\mathrm{C}$ primary afferents, perhaps particularly the former, which are chiefly responsible for cold and pinprick sensations.

Table 8 shows that the deficit for pinprick, warm, and cold sensations, but not hot pain, is greater in areas of greatest pain than in areas of less pain, whereas there is no significant difference in deficit between greatest and least pain areas for tactile, vibratory (the latter perhaps because of methodological difficulties), two point discrimination, skinfold pinch, and hot pain sensations. In 16 cases of spinal cord injury, Eide et $a l^{53}$ have found that the quantitative increase in warm and cold thresholds was greater in painful than in adjacent nonpainful areas with sensory deficit; but that in the case of hot pain, the difference was considerably less; whereas tactile (von Frey) sensibility loss was greater in non-painful than in painful areas.

It seems, therefore, that the intensity of ongoing pain in these patients is proportional to the degree of deficit for pinprick and thermal (perhaps particularly cold) sensations, but is uninfluenced by the degree, or even the presence or absence, of deficit for low threshold mechanical submodalities, and perhaps also skinfold pinch (tissue damage pain). Asbury ${ }^{54}$ noted that deficits for cold and pinprick sensations are essential in the case of painful peripheral neuropathies. The critical disorder in central pain also seems to lie in the central processing of information coming from $A \delta$ (cold and pinprick) rather than $A \beta$ or $C$ peripheral afferents; this adds further relevance to the finding of Yarnitsky and Ochoa ${ }^{36}$ that paradoxical burning sensation follows blockade of cold specific myelinated fibres in the periphery.

As reported elsewhere, ${ }^{55}$ there is a striking difference between supraspinal and spinal lesions with respect to skinfold pinch (mechanonociceptive) thresholds. It is far more severely affected in spinal than in supraspinal lesions; and this of course has implications for the anatomy of the "pain pathway". 55

In this respect, interpretation of even the recent medical literature is often bedevilled by the fact that many authors refer to an unspecified stimulus described as "pain", without stating by what means it is produced; regrettably, it transpires that "pinprick" is often, though confusingly not necessarily, what is meant.

Starting with Dejerine and Roussy ${ }^{1}$ themselves, and reiterated by Garcin, $^{6}$ many authors have remarked on the lack of response of central pain to (conventional) analgesics. This is hardly surprising, as there is obviously no stimulation of peripheral nociceptors, and lesions of central pathways conducting impulses generated in them (for example, anterolateral cordotomy) are ineffective in alleviating central neurogenic pain; it is their action on synapses in these classic "pain pathways" whereby opioids relieve pain from tissue damage. It is an astounding fact that large numbers of well informed authors who quote (a) many references attesting that those (wide dynamic range, convergent) neurons in the spinal grey matter which respond to noxious stimulation project exclusively into the anterolateral funiculus (see Willis ${ }^{56}$ ), and (b) further references showing that anterolateral cordotomy and mesencephalic tractotomy as well as opioids are usually ineffective in the relief of neurogenic pain, nevertheless attempt to explain central pain in terms of discharge from just these wide dynamic range or convergent neurons.

The hypothesis has been put forward elsewhere ${ }^{55}$ that the development of pain (or not) after lesions in the classic (neo)spinothalmic pathway and its projections ${ }^{8}$ may depend on the up regulation or down regulation of (probably noradrenergic) transmitter receptors; the initial level of such receptors could also explain the time course of pain development.

Whatever may be the true pathophysiology of central pain, it has been found that some two thirds of patients can be relieved by treatment with adrenergically active antidepressants. ${ }^{50}$ (Hence the suggestion that noradrenergic receptors may be implicated.) These drugs are more effective the sooner they are prescribed after pain onset. In some cases in which antidepressants alone are not effective, relief may be gained by the addition of oral mexiletine. ${ }^{50}$ To obtain maximal effect from adrenergically active antidepressants, it is important not to lose time by "trying" the effect of classic analgesics, which are virtually devoid of action in central and other neurogenic pains. ${ }^{57}$ 
Thanks are due to Drs J Lahuerta, T Nurmikko, C Ramamoorthy, J A Campbell, Mrs C Haggett, and Miss S Edwards, who carried out some of the quantitative sensory perception threshold and autonomic function tests.

1 Dejerine J, Roussy J. Le syndrome thalamique. Rev Neurol 1906;14:521-32.

2 Head H, Holmes G. Sensory disturbances from cerebral lesions. Brain 1911;34:102-254.

3 Davison C, Schick W. Spontaneous pain and other sensory disturbances. Arch Neurol Psychiatry 1935;34:1204-37.

4 Retif J, Brihaye J, Vanderhaegen JJ. Syndrome douloureux "thalamique" et lésion pariétale. A propos de trois observations de tumeur à localisation pariétale, s'étant accompagnées de douleurs spontanées de l'hemicorps

5 Michel D, Laurent B, Convers P, et al. Douleurs corticales. Etude clinique, électrophysiologique et topographique de 12 cas. Rev Neurol 1990;46:405-14.

6 Garcin R. La douleur dans les affections organiques du système nerveux central. Rev Neurol 1937;68:105-53.

7 Ajuriaguerra $\mathrm{J}$ de. La douleur dans les affections du système nerveux central. Paris: Doin, 1937.

8 Cassinari V, Pagni CA. Central pain. A neurosurgical survey. Cambridge, MA: Harvard University Press, 1969.

9 Agnew DC, Shetter AG, Segall HD, Flom RA. Thalamic pain. Adv Pain Res Ther 1983;5:941-6.

10 Bowsher D, Lahuerta J, Brock LG. Twelve cases of central pain, only three with thalamic lesions. Pain 1984;suppl 2.83.

11 Bowsher D, Lahuerta J, Brock LG. A note on the relationship between site of interruption and somatosensory thresholds in lesions of human pain pathway. In: Schmidt $\mathrm{RF}$ et al, eds. Fine afferent nerve fibers and pain. Weinheim: VCH Gesellschaft, 1987:452-9.

12 Bowsher D, Smith T, Lewis-Jones H, Leijon G. Magnetic resonance pathology of central post-stroke pain (CPSP) Proceedings of the XIth international congress of neuropathology, 1990: 384 .

13 Lewis-Jones H, Smith T, Bowsher D, Leijon G. Magnetic resonance imaging in 36 cases of central post-stroke pain (CPSP). Pain 1990;suppl 5:S278.

14 Bowsher $\mathrm{D}$, Lahuerta J. Central pain in 22 patients: clinical features, somatosensory changes, and CT-scan findings. f Neurol 1985;232 (suppl): 297 .

15 Leijon G, Bowsher D. Somatosensory findings in central post-stroke pain (CPSP) and controls. Pain 1990;suppl 5:S468

16 Bowsher D, Leijon G, Smith T. Pathophysiology of poststroke pain. Neurosci Lett 1990;suppl 40:S4

17 Leijon G, Boivie J, Johansson I. Central post-stroke paina study of the mechanisms through analyses of the sensory abnormalities. Pain 1989;37:173-85.

18 Gonzales GR, Herskovitz S, Rosenblum M, et al. Central pain from cerebral abscess: thalamic syndrome in AIDS patients with toxoplasmosis. Neurology 1992;42: $1107-9$.

19 Salles AAF de, Bittar GT. Thalamic pain syndrome: anatomic and metabolic correlation. Surg Neurol 1994; 41:147-51

20 Garcin R. Thalamic syndrome and pain of central origin. In: Soulairac A, Cahn J, Charpentier J, eds Pain. London: Academic Press, 1968:521-41.

21 Beric A, Dimitrijevic MR, Lindblom U. Central dysesthesia syndome in spinal cord injury patients. Pain 1988;34:109-16.

22 Pelser H, van Gijn J. Spinal infarction. A follow-up study. Stroke 1993;24:896-8.

23 Ho KL. Uncommon causes of the lateral medullary syndrome-Report of a case of metastatic carcinoma. Arch Neurol 1980;37:669-70.

24 Lahuerta J, Bowsher D, Buxton PH, Lipton S. Percutaneous cervical cordotomy: a review of 181 operations in 146 patients, including a study on the location of "pain fibers" in the second cervical spinal cord segment "pain fibers" in the second cervical spinal

25 Melzack R. The McGill pain questionnaire: major properties and scoring methods. Pain 1975;1:277-99.

26 Bowsher DR, Foy PM, Shaw MDM. Central pain complicating infarction following subarachnoid haemorrhage. Br F Neurosurg 1989;3:435-43.

27 Chan AW, Campbell JA, Bowsher D. Weighted pinprick sensory thresholds: a simple test of sensory function in diabetic peripheral neuropathy. $f$ Neurol Neurosurg Psychiatry 1992;55:56-9.

28 Fruhstorfer H, Lindblom U, Schmidt WG. Method for quantitative estimation of thermal thresholds in patients. $\mathcal{F}$ Neurol Neurosurg Psychiatry 1976;39:1071-5.
29 Bowsher D. Cerebrovascular Disease: Sensory consequences of stroke. Lancet 1993;341:156

30 Andersen G, Vestergaard $\mathrm{K}$, Ingeman-Nielsen, $M$, Jensen TS. Incidence of central post-stroke pain. Pain 1995;61: 187-94.

31 Leijon G, Boivie J, Johansson I. Central post-stroke painneurological symptoms and pain characteristics. Pain 1989;36:13-25.

32 Vestergaard $K$, Nielsen J, Andersen G, Ingeman-Nielsen $M$, Arendt-Nielsen L, Jensen TS. Sensory abnormalities in consecutive, unselected patients with central postin consecutive, unselected patien

33 Stoodley MA, Warren JD, Oatey PE. Thalamic syndrome caused by unruptured cerebral aneurysm. Case report. $\mathcal{f}$ Neurosurg 1995;82:291-3.

34 Boivie J, Leijon G. Pain and altered sensation in patients with central post-stroke pain. In: Dimitrievic MR, Eccles JC, Wall PD, eds. Altered sensation and pain. Berlin: Karger, 1990:42-55.

35 Boivie J, Leijon G. Clinical findings in patients with central poststroke pain. In: Casey KL, ed. Pain and central nervous system disease: the central pain syndromes. New York: Raven Press, 1991:65-75.

36 Yarnitsky D, Ochoa, JL. Release of cold-induced burning pain by block of cold-specific afferent input. Brain pain by block of

37 Craig $\mathrm{AD}$, and Bushnell MC. The thermal grill illusion unmasking the burn of cold pain. Science 1994;265: 252-5.

38 Bowsher D. Acute shingles and postherpetic neuralgia: Effects of acyclovir and outcome of treatment with amitriptyline. Br f Gen Prac 1991;42:244-6.

39 Garcin R, Lapresle J. Deuxième observation personelle de syndrome sensitive de type thalamique et à topographie cheiro-orale par lésion localisée du thalamus. Rev Neurol 1960;103:474-81.

40 Lenz FA, Dostrovsky JO, Tasker RR, Yamashiro K, Kwan HC, Murphy JT. Single-unit analysis of the human ventral thalamic nuclear group: somatosensory responses. $\mathcal{F}$ Neurophysiol 1988;59:299-316.

41 Kameyama M. Vascular lesions of the thalamus on the dominant and nondominant side. Appl Neurophysiol dominant and no

42 Riddoch, G. The clinical features of central pain. Lancet 1938;i:1093-8;1150-6;1205-9.

43 Davison C, Goodhart SP, Savitsky N. The syndrome of the superior cerebellar artery and its branches. Archives of Neurology and Psychiatry (Chicago) 1935;33:1143-74

44 Lievens P. Mémoire pour le titre d'assistant etranger. Paris: Faculté de Médecine, 1958

45 Hommel M, Besson G, Pollak P, Borgel F, Le Bas JF, Perret J. Pure sensory stroke due to a pontine lacune. Stroke 1989;20:406-8.

46 Stenuit A, Retif J. Syndrome thalamique de DejerineRoussy: Présentation d'une observation et discussion. Rev Méd Brux 1984;5:21-5.

47 Spiller WG. Central pain in syringo-myelia and dysesthesia and overreaction to sensory stimuli in lesions below the optic thalamus. Archives of Neurology and Psychiatry optic thalamus. Archives

48 Nurmikko T, Bowsher D. Somatosensory findings in postherpetic neuralgia. F Neurol Neurosurg Psychiatry 1990; 53:135-4

49 Nurmikko T, Wells C, Bowsher D. Pain and allodynia in postherpetic neuralgia: role of somatic and sympathetic systems. Acta Neurol Scand 1991;84:146-52.

50 Bowsher D. The management of central post-stroke pain Postgrad Med f 1995;71:598-604.

51 Korpelainen JT, Sotaniemi KA, Myllyl VV. Asymmetric sweating in stroke. A prospective quantitative study of patients with hemispheral brain infarction. Neurology 1993;43:1211-4.

52 Schmahmann JD, Leifer D. Parietal pseudothalamic pain syndrome: clinical features and anatomic correlates. Arch Neurol 1992;49:1032-7.

53 Eide PK, Jørum E, Stenehjem AE. Somatosensory findings in patients with spinal cord injury and central dysaesthesia pain. F Neurol Neurosurg Psychiatry 1996;60:411-5.

54 Asbury AK. Pain in generalised neuropathies. In: Fields $\mathrm{HL}$, ed. Pain syndromes in neurology. London Butterworth, 1990:131-41.

55 Bowsher, D. Central pain. Pain Rev 1995;2:175-86.

6 Willis WD. The spinothalamic tract in primates. In: Besson JM, Guilbaud G, Peschanski M, eds. Thalamus and pain. Amsterdam: Excerpta Medica, 1987:35-47.

57 Bowsher D. Neurogenic pain syndromes and their management. Br Med Bull 1991;47:644-66. 